\title{
ChemComm
}

Cite this: Chem. Commun., 2013, 49, 3449

Received 14th January 2013, Accepted 4th March 2013

DOI: $10.1039 / c 3 c c 00309 d$

\section{Positively charged bulk Au particles as an efficient catalyst for oxidation of styrene with molecular oxygen $\dagger$}

\author{
Liang Wang, ${ }^{\mathrm{b}}$ Bingsen Zhang, ${ }^{\mathrm{c}}$ Wei Zhang, ${ }^{\mathrm{d}}$ Jian Zhang, ${ }^{\mathrm{a}}$ Xionghou Gao, \\ Xiangju Meng, ${ }^{a}$ Dang Sheng Su*cd and Feng-Shou Xiao*a
}

www.rsc.org/chemcomm

Positively charged bulk Au particles with size of 20-150 $\mathrm{nm}$ were formed on amino-modified porous polydivinylbenzene (Au/PN), which showed superior catalytic performance and good recyclability in the aerobic oxidation of styrene.

Since the pioneering work of Hutchings and Haruta et al., ${ }^{1} \mathrm{Au}$ catalysts have been demonstrated to be active for many important reactions, especially for oxidation by molecular oxygen, ${ }^{2-7}$ where a critical factor for determining the catalytic performance is the particle size of the Au catalysts. When the Au particle sizes are over $5 \mathrm{~nm}$, the Au catalysts are normally of low-efficiency. ${ }^{4 a, 6,8}$

As an important model reaction for the production of fine chemicals and pharmaceuticals, the oxidation of styrene has been widely investigated over various Au catalysts. ${ }^{2,9-14}$ For the liquid-phase oxidation of styrene by molecular oxygen, additives (e.g. $t$-butyl hydroperoxide) as the initiator are necessary. ${ }^{2,11,12}$ However, when the size of Au particles is extremely small ( $\sim 1.4 \mathrm{~nm}, 55$ atoms, or $\sim 0.9 \mathrm{~nm}, 25$ atoms), the $\mathrm{Au}$ catalysts are very active even in the absence of additives. ${ }^{9,10}$ In contrast, when the size of Au particles is $2 \mathrm{~nm}$, they become completely inactive. Notably, the synthesis of extremely small $\mathrm{Au}$ nanoparticles usually requires precursor ligands in the starting step and the removal of the precursor ligands in the final step, which is expensive and could produce undesirable waste. ${ }^{8 b, 9,10}$ In addition, extremely small $\mathrm{Au}$ nanoparticles are unstable in catalytic oxidations due to their aggregation. As a result, their catalytic activity reduces significantly for long

\footnotetext{
${ }^{a}$ Key Laboratory of Applied Chemistry of Zhejiang Province, Zhejiang University, Hangzhou 310028, China. E-mail: fsxiao@zju.edu.cn

${ }^{b}$ State Key Laboratory of Inorganic Synthesis and Preparative Chemistry, Jilin University, Changchun 130012, China

${ }^{c}$ Shenyang National Laboratory of Materials Science, Institute of Metal Research, Chinese Academy of Science, Shenyang 110016, China.

E-mail: dangsheng@fhi-berlin.mpg.de

${ }^{d}$ Department of Inorganic Chemistry, Fritz Haber Institute of the Max Planck Society, Berlin 14195, Germany

${ }^{e}$ Lanzhou Petrochemical Research Center, Petrochemical Research Institute, Petro China Company Limited, Lanzhou 730060, China

$\dagger$ Electronic supplementary information (ESI) available. See DOI: 10.1039/c3cc00309d
}

reactions, ${ }^{9}$ which strongly limits the wide application of $\mathrm{Au}$ nanoparticle catalysts with extremely small particle size.

Here, we demonstrate an alternative catalyst of amino functionalized, porous polydivinylbenzene supported, positively charged bulk $\mathrm{Au}$ particles $(\mathrm{Au} / \mathrm{PN})$ with particle sizes of 20-150 nm, which are very stable and active in the aerobic oxidation of styrene. This result is quite different from the known fact that only Au particles with a size smaller than $2 \mathrm{~nm}$ are catalytically active and stable for the aerobic oxidation of styrene in the absence of initiators. ${ }^{9,15}$

The Au/PN sample is synthesized from the one-pot treatment of amino functionalized porous polydivinylbenzene with $\mathrm{HAuCl}_{4}$ solution. The choice of amino groups is due to our careful investigation of the interaction between the $\mathrm{HAuCl}_{4}$ solution with various amines. Fig. S1 (ESI $\dagger$ ) shows the photographs and UV-Visible spectra of mixtures of the $\mathrm{HAuCl}_{4}$ solution with different amines. When the aliphatic amines cyclohexylamine and ethylenediamine were added into the $\mathrm{HAuCl}_{4}$ solution, the mixture still exhibited a yellow color, which was very similar to the color of the pure $\mathrm{HAuCl}_{4}$ solution (Fig. S1A, ESI $\dagger$ ). In addition, the mixture of cyclohexylamine and $\mathrm{HAuCl}_{4}$ exhibited a similar UV-Visible spectra (Fig. S1B-c, ESI $\dagger$ ) to the pure $\mathrm{HAuCl}_{4}$ (Fig. S1B-a, ESI $\dagger$ ), indicating that the valence of $\mathrm{Au}$ cations was stable in the mixture of cyclohexylamine with $\mathrm{HAuCl}_{4}$. Interestingly, when aniline was added into the $\mathrm{HAuCl}_{4}$ solution, the color immediately changed to dark brown. In comparison with the UV-Vis spectra of pure $\mathrm{HAuCl}_{4}$ solution (Fig. S1B-a, ESI $\dagger$ ) and pure aniline (Fig. S1B-d, ESI $\dagger$ ), the dark brown mixture showed clear additional signals in the wavelength of 500-700 nm (Fig. S1B-e, ESI $\dagger$ ), which are associated with the presence of metallic Au. ${ }^{16}$ These results indicate that metallic $\mathrm{Au}$ species could be formed by the interaction between aniline and Au cations.

Based on the interaction between aniline and Au cations, it is suggested that amino-modified porous polydivinylbenzene (PN) should be a suitable support for the formation of metallic $\mathrm{Au}$ species as a heterogeneous catalyst ( $\mathrm{Au} / \mathrm{PN})$. Fig. 1A shows the synthesis scheme of $\mathrm{Au} / \mathrm{PN}$ where the $\mathrm{Au}$ content is about 2.4 wt\% (Table S1, ESI $\dagger$ ). 


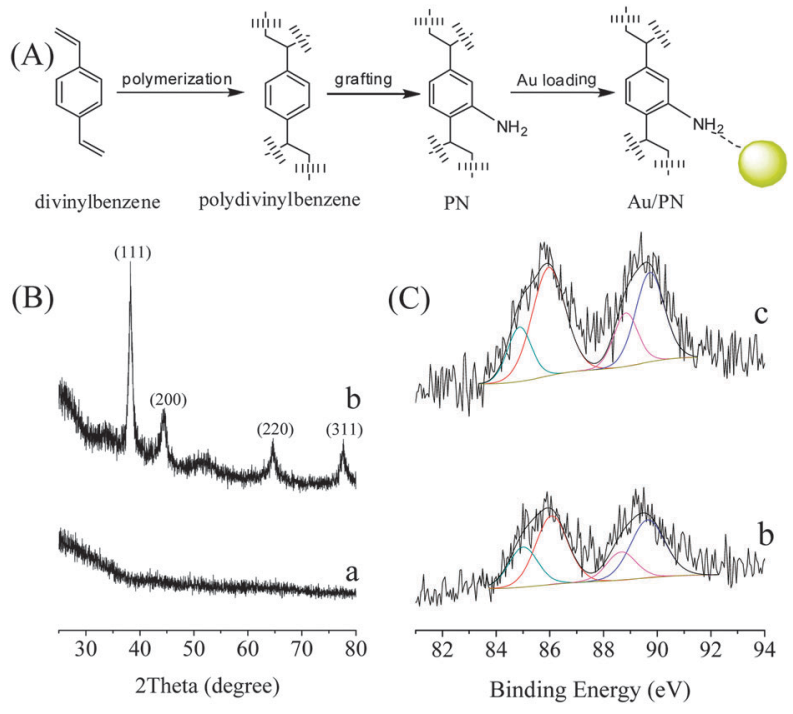

Fig. 1 (A) Scheme, (B) XRD, and (C) Au4f XPS spectra of (a) PN, (b) Au/PN, and (c) Au/PN-R

The presence of amino groups on polydivinylbenzene was confirmed by IR and N1s XPS techniques (Fig. S2, ESI $\dagger$ ). In addition, the XRD pattern of $\mathrm{Au} / \mathrm{PN}$ shows four obvious peaks at $38.3,44.5,64.7$, and $77.7^{\circ}$, which are attributed to the (111), (200), (220), and (311) incidences of a typical metallic $\mathrm{Au}$ species (Fig. 1B). Notably, these peaks are narrow and sharp, suggesting a relatively large particle size of metallic Au. ${ }^{16}$ Furthermore, the UV-Vis spectrum of Au/PN gives an obvious peak at $518 \mathrm{~nm}$ (Fig. S3, ESI $\dagger$ ), confirming the presence of metallic $\mathrm{Au}$ species in the $\mathrm{Au} / \mathrm{PN}$ sample, ${ }^{16}$ in good agreement with the results of the XRD patterns (Fig. 1B).

Fig. 2 shows the microscopic characterization of $\mathrm{Au} / \mathrm{PN}$. In the STEM image, the Au particles with large sizes of 20-150 nm are clearly observed on the porous PN support (Fig. 2a and b). The elemental mapping shows that the $\mathrm{C}$ and $\mathrm{N}$ species are

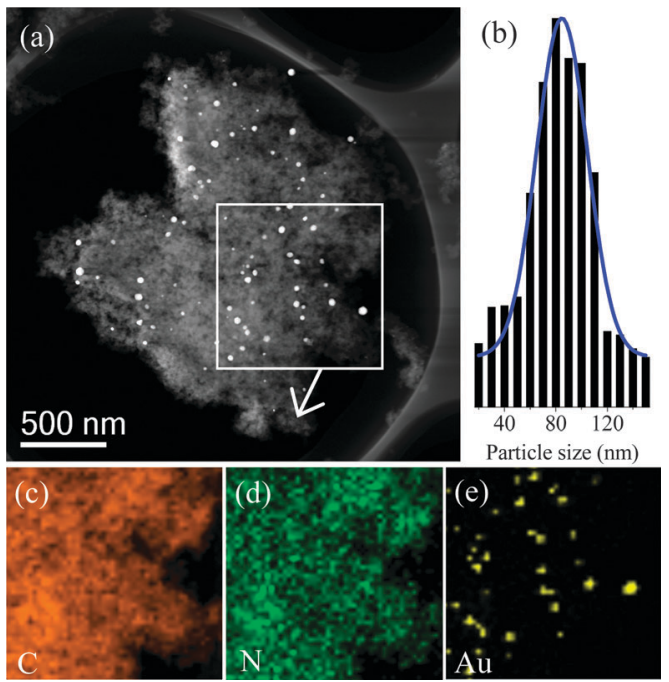

Fig. 2 (a) STEM image, (b) particle size distribution, (c-e) C, N, and Au elemental maps of Au/PN. homogeneously distributed on the Au/PN sample (Fig. 2c and d). Notably, the distribution of Au particles in the STEM image (the white square in Fig. 2a) is highly consistent with the distribution of $\mathrm{Au}$ species in the $\mathrm{Au}$ elemental mapping (Fig. 2e). A similar result could also be found in various areas of the $\mathrm{Au} / \mathrm{PN}$ sample (Fig. S4, ESI $\dagger$ ), indicating that the $\mathrm{Au}$ species on the $\mathrm{Au} / \mathrm{PN}$ are present as bulk $\mathrm{Au}$ particles. Additionally, the HRTEM images show that extremely small Au nanoparticles could not be detected on the Au/PN (Fig. S5, ESI $\dagger$ ), which supports that only bulk Au particles exist in the $\mathrm{Au} / \mathrm{PN}$ sample.

Although the bulk metallic Au particles have been confirmed on the $\mathrm{Au} / \mathrm{PN}$ sample, it is still desirable to investigate the electronic properties of the $\mathrm{Au}$ species on the surface of the bulk Au. Fig. 1C shows the Au4f XPS spectra of various samples. Interestingly, the Au4f XPS spectrum of $\mathrm{Au} / \mathrm{PN}$ shows obvious $\mathrm{Au}_{4 / 2}$ peaks at 86.0 and $84.9 \mathrm{eV}$ associated with typical $\mathrm{Au}^{3+}$ and $\mathrm{Au}^{+}$species, respectively. ${ }^{17}$ These results indicate that there are positively charged $\mathrm{Au}$ species on the surface of the bulk $\mathrm{Au}$ particles (Table S1, ESI $\dagger$ ). The EPR spectra show that PN gives the signal at $g=2.0045$, while $\mathrm{Au} / \mathrm{PN}$ has an additional strong signal $(g=2.3262$ ), which is reasonably assigned to the positively charged $\mathrm{Au}$ species (Fig. S6, ESI $\dagger$ ) because the pure metallic $\mathrm{Au}$ is EPR-silent. ${ }^{18}$ In combination of the results obtained from the XPS and EPR techniques, we could conclude that the bulk $\mathrm{Au}$ particles of $\mathrm{Au} / \mathrm{PN}$ are rich in Au cations. Very surprisingly, the Au cations on $\mathrm{Au} / \mathrm{PN}$ are extremely stable. For example, after reduction of the $\mathrm{Au} / \mathrm{PN}$ sample by $\mathrm{NaBH}_{4}$, the obtained Au/PN-R still shows similar Au4f XPS (Fig. 1C-c, Table S1, ESI $\dagger$ ) and EPR spectra (Fig. S6-c, ESI $\dagger$ ) to those of the as-synthesized $\mathrm{Au} / \mathrm{PN}$. These results indicate that the $\mathrm{Au}$ cations on $\mathrm{Au} / \mathrm{PN}$ have extraordinarily high stability, which might be related to the interaction between the aniline groups and the Au species.

For comparison, the aliphatic amino functionalized mesoporous silica was synthesized by coating aminopropyltriethoxysilane (KH-550) on the surface of MCM-41 (MCM-N, Scheme S1, ESI $\dagger$ ). When the Au species were loaded on MCM-N (Au/MCM-N), the metallic Au nanoparticles were undetectable from the XRD pattern (Fig. S7, ESI $\dagger$ ). After reduction with $\mathrm{NaBH}_{4}, \mathrm{Au}^{3+}$ cations were undetectable on the Au/MCM-N sample, indicating that $\mathrm{Au}^{3+}$ cations are unstable in the presence of $\mathrm{NaBH}_{4}$ (Fig. S7-S9, ESI $\dagger$ ), which is quite distinguishable from the phenomenon of the $\mathrm{Au} / \mathrm{PN}$ sample with very stable $\mathrm{Au}$ cations.

Table 1 presents the catalytic data of various Au catalysts in the direct aerobic oxidation of styrene. The PN support is completely inactive for this reaction (entry 1 in Table 1). However, the $\mathrm{Au} / \mathrm{PN}$ catalyst shows high styrene conversion at $27.0 \%$, with selectivity towards styrene epoxide at 30\% (entry 2 in Table 1, Fig. S12, ESI $\dagger$ ). In comparison, the non-porous supported $\mathrm{Au}$ particles (Au/non-porous PN, Table S1, Fig. S10 and S11, ESI $\dagger$ ) with similar Au particle sizes and cations, show styrene conversion at $\mathbf{1 4 . 2 \%}$ (entry 5 in Table 1, Table S2, ESI $\dagger$ ). The extremely small Au nanoparticles $(\sim 1.4 \mathrm{~nm})$ supported on boron nitride $\left(\mathrm{Au}_{55} / \mathrm{BN}\right)$ and $\mathrm{SiO}_{2}\left(\mathrm{Au}_{55} / \mathrm{SiO}_{2}\right)$, which were reported as very efficient catalysts for the aerobic oxidation of styrene, show styrene conversion at 19.2 and 25.8, with styrene epoxide selectivity at 12-14\% (entries 6 and 7 in Table 1). 
Table 1 Catalytic data of various Au catalysts in the aerobic oxidation of styrene $^{a}$

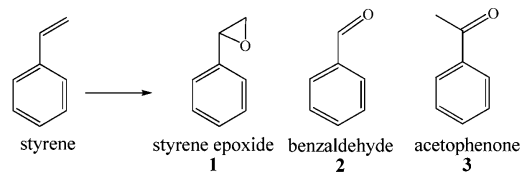

\begin{tabular}{|c|c|c|c|c|c|c|c|}
\hline \multirow[b]{2}{*}{ Entry } & \multirow[b]{2}{*}{ Catalyst } & \multirow[b]{2}{*}{ Conv. (\%) } & \multicolumn{4}{|c|}{ Product selectivity $^{b}(\%)$} & \multirow[b]{2}{*}{ Ref. } \\
\hline & & & P1 & P2 & P3 & P4 & \\
\hline 1 & PN & Inactive & & & & & This work \\
\hline 2 & $\mathrm{Au} / \mathrm{PN}$ & 27.0 & 30.0 & 65.2 & 2.8 & 2.0 & This work \\
\hline $3^{c}$ & $\mathrm{Au} / \mathrm{PN}$ & 16.4 & 22.2 & 67.2 & 10.6 & - & This work \\
\hline $4^{d}$ & $\mathrm{Au} / \mathrm{PN}$ & 24.9 & 31.2 & 64.8 & 2.1 & 1.9 & This work \\
\hline 5 & $\mathrm{Au} /$ non-porous $\mathrm{PN}$ & 14.2 & 29.1 & 60.2 & 3.3 & 7.4 & This work \\
\hline 6 & $\mathrm{Au}_{55} / \mathrm{BN}$ & 19.2 & 14.0 & 82.3 & 3.9 & & 9 \\
\hline 7 & $\mathrm{Au}_{55} / \mathrm{SiO}_{2}$ & 25.8 & 12.0 & 82.1 & 5.7 & & 9 \\
\hline 8 & $\mathrm{Au} / \mathrm{MCM}-\mathrm{N}-\mathrm{R}$ & Inactive & & & & & This work \\
\hline 9 & $\mathrm{Au} / \mathrm{MCM}-\mathrm{N}$ & Inactive & & & & & This work \\
\hline $10^{e}$ & $\mathrm{HAuCl}_{4}$ & Inactive & & & & & This work \\
\hline 11 & $\mathrm{Au} / \mathrm{PN}-\mathrm{R}$ & 27.1 & 29.0 & 65.7 & 3.1 & 2.2 & This work \\
\hline
\end{tabular}

These results indicate that the $\mathrm{Au} / \mathrm{PN}$ catalyst is very active (Fig. S13, ESI $\dagger$ ).

In contrast, the $\mathrm{Au} / \mathrm{MCM}-\mathrm{N}-\mathrm{R}$ catalyst with small $\mathrm{Au}$ nanoparticles of 2.0-3.4 nm (Fig. S9 and Table S1, ESI $\dagger$ ) is completely inactive for this reaction (entry 8 in Table 1 ). ${ }^{9}$ Additionally, both the $\mathrm{Au} / \mathrm{MCM}-\mathrm{N}$ and $\mathrm{HAuCl}_{4}$ catalysts, which have only $\mathrm{Au}^{3+}$ cations, are also inactive for this reaction (entries 9 and 10 in Table 1). These results might suggest that the $\mathrm{Au}^{0}$ on the $\mathrm{Au}$ particles $(>2 \mathrm{~nm})$ or $\mathrm{Au}^{3+}$ sites are not the active centres for the aerobic oxidation of styrene. Based on these results, it might be suggested that the $\mathrm{Au}^{+}$sites on $\mathrm{Au} / \mathrm{PN}$ are the active sites for the oxidation of styrene, because the $\mathrm{Au}^{+}$sites have similar Au4f $\mathrm{f}_{7 / 2}$ electron binding energy $(85.0 \mathrm{eV})$ to that of the $\mathrm{Au}_{55}$ clusters

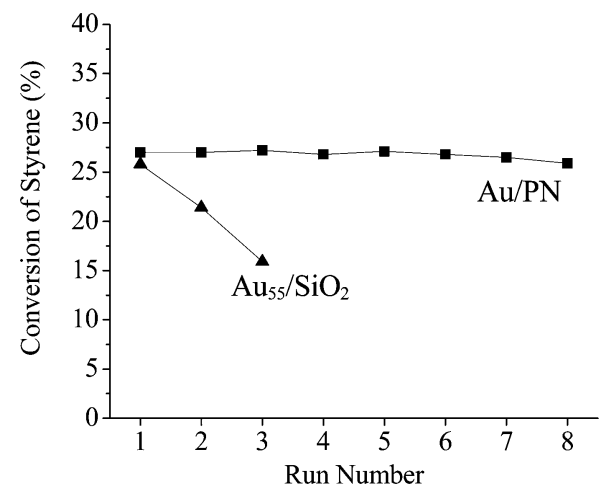

Fig. 3 Aerobic oxidation of styrene using Au/PN and $\mathrm{Au}_{55} / \mathrm{SiO}_{2}$ catalysts over several cycles. The data for the $\mathrm{Au}_{55} / \mathrm{SiO}_{2}$ catalyst is from ref. 9.
(85.1 eV), suggesting their similar electronic properties which might lead to unusual catalytic performances. ${ }^{9,17,19}$

It is very important to point out that there is no leaching for the $\mathrm{Au} / \mathrm{PN}$ catalyst. For example, after filtrating the used $\mathrm{Au} / \mathrm{PN}$ catalyst, the $\mathrm{Au}$ concentration in the liquor is less than $3 \mathrm{ppb}$ (ICP analysis). More importantly, Au/PN has very excellent recyclability. Even when recycled 7 times, the sample still exhibits very similar activities (Fig. 3). On the contrary, the $\mathrm{Au}_{55} / \mathrm{SiO}_{2}$ catalyst loses most of its activity after two further cycles under the same reaction conditions (Fig. 3), because the $\mathrm{Au}_{55}$ clusters are not stable and aggregate into relatively large nanoparticles during the reaction process. ${ }^{9}$

This work is supported by the National Natural Science Foundation of China (20973079 and U1162201) and State Basic Research Project of China (2009CB623501). Bingsen Zhang gratefully acknowledge the financial support provided by the IMR SYNL-T.S. Kê Research Fellowship, the National Natural Science Foundation of China (No. 21203215), and the China Postdoctoral Science Foundation (2012M520652).

\section{Notes and references}

1 (a) G. J. Hutchings, J. Catal., 1985, 96, 292; (b) M. Haruta, T. Koboyashi, H. Sano and N. Yamada, Catal. Lett., 1987, 16, 405.

2 M. D. Hughes, Y.-J. Xu, P. Jenkins, P. McMorn, P. Landon, D. I. Enache, A. F. Carley, G. A. Attard, G. J. Hutchings, F. King, E. H. Stitt, P. Johnston, K. Griffin and C. J. Kiely, Nature, 2005, 437, 1132.

3 (a) A. Corma and H. Garcia, Chem. Soc. Rev., 2008, 37, 2096; (b) D. P. He, H. Shi and B.-Q. Xu, Green Chem., 2007, 9, 849; (c) F.-Z. Su, Y.-M. Liu, L.-C. Wang, Y. Cao, H.-Y. He and K.-N. Fan, Angew. Chem., Int. Ed., 2008, 47, 334.

4 (a) A. Abad, P. Concepcion, A. Corma and H. Garcia, Angew. Chem., Int. Ed., 2005, 44, 4066; (b) J. C. F. Gonzales and B. C. Gates, Chem. Soc. Rev., 2008, 37, 2127.

5 (a) X. Zhang, H. Shi and B.-Q. Xu, Angew. Chem., Int. Ed., 2005, 44, 7132; (b) C. Y. Ma, Z. Mu, J. J. Li, Y. G. Jin, J. Cheng, G. Q. Lu, Z. P. Hao and S. Z. Qiao, J. Am. Chem. Soc., 2010, 132, 2608; (c) W. Yan, S. Brown, Z. Pan, S. M. Mahurin, S. H. Overbury and S. Dai, Angew. Chem., Int. Ed., 2006, 45, 3614.

6 S. Abraham, I. Kim and C. A. Batt, Angew. Chem., Int. Ed., 2007, 46, 5720 .

7 (a) L. Wang, W. Zhang, D. S. Su, X. Meng and F.-S. Xiao, Chem. Commun., 2012, 48, 5476; (b) P. Liu, Y. Guan, R. A. van Santen, C. Li and E. J. M. Hensen, Chem. Commun., 2011, 47, 11540.

8 (a) M. Stratakis and H. Garcia, J. Am. Chem. Soc., 2012, 112, 4469; (b) H. Tsunoyama, N. Ichikuni, H. Sakuria and T. Tsukuda, J. Am. Chem. Soc., 2009, 131, 7086.

9 M. Turner, V. B. Golovko, O. P. H. Vaughan, P. Abdulkin, A. Berenguer-Murcia, M. S. Tikhov, B. F. G. Johnson and R. M. Lambert, Nature, 2008, 454, 981.

10 Y. M. Liu, H. Tsunoyama, T. Akita and T. Tsukuda, Chem. Commun., 2010, 46, 550 .

11 L. Wang, H. Wang, P. Hapala, L. Zhu, L. Ren, X. Meng, J. P. Lewis and F.-S. Xiao, J. Catal., 2011, 281, 30.

12 F.-X. Zhu, W. Wang and H.-X. Li, J. Am. Chem. Soc., 2011, 133, 11632.

13 X. Deng and C. M. Friend, J. Am. Chem. Soc., 2005, 127, 17178.

14 Y. Zhu, H. Qian, M. Zhu and R. Jin, Adv. Mater., 2010, 22, 1915.

15 H. G. Boyen, G. Kastle, F. Weigl, B. Koslowaki, C. Dietrich, P. Ziemann, J. P. Spatz, S. Riethmuller, C. Hartmann, M. Moller, G. Schmid, M. G. Garnier and P. Oelhafen, Science, 2002, 297, 1533.

16 L. Wang, X. Meng, B. Wang, W. Chi and F.-S. Xiao, Chem. Commun., 2010, 46, 5003.

17 R. Si and M. Flytzani-Stephanopoulos, Angew. Chem., Int. Ed., 2008, 47, 2884 .

18 B. Chowdhury, J. J. Bravo-Suarez, N. Mimura, J. Lu, K. K. Bando, S. Tsubota and M. Haruta, J. Phys. Chem. B, 2006, 110, 22995.

19 L. K. Ono, D. Sudfeld and B. R. Cuenya, Surf. Sci., 2006, 600, 5041. 